\title{
OPIATE ALKALOIDS ANTAGONIZE POSTSYNAPTIC GLYCINE AND GABA RESPONSES: CORRELATION WITH CONVULSANT ACTION
}

\author{
MARY ANN WERZ and ROBERT L. MACDONALD*
}

Neurosciences Program and (R.L.M.) Department of Neurology, University of Michigan Medical Center, Neuroscience Laboratory Building, 1103 East Huron, Ann Arbor, MI 48109 (U.S.A.)

(Accepted August 20th, 1981)

Key words: opiate - glycine - GABA - inhibition - convulsant

\section{SUMMARY}

Opiate alkaloid and opioid peptide actions on spontaneous neuronal activity and postsynaptic amino acid responsiveness were assessed using intracellular recording techniques applied to murine spinal cord neurons in primary dissociated cell culture. Application of opiates was by superfusion and amino acids by iontophoresis. Glycine and GABA but not glutamate responses were antagonized by the opiate alkaloids. Since opiate effects on glycine and GABA responses were not naloxonereversible, only weakly stereospecific, and not produced by the opioid peptide [D$\mathrm{Ala}^{2}$ ]-Met-enkephalinamide, it is unlikely that these effects were mediated by opiate recep:ors. Opiate depression of glycine inhibition was correlated with the induction of paroxysmal depolarizations in cultured spinal cord neurons, suggesting that antagonism of inhibitory amino acid transmission may underlie the convulsant actions of high concentrations of the opiate alkaloids.

\section{INTRODUCTION}

Accumulating evidence indicates that opiates have several distinct inhibitory actions, including presynaptic depression of transmitter release ${ }^{25,30,36}$, direct postsynaptic hyperpolarization ${ }^{38,39}$ and postsynaptic antagonism of amino acid responses ${ }^{6,14-16,28,53,55}$. In addition, opiates have been reported to have excitatory actions $^{6,11,12,21}$. While several of these actions might be attributable to activation of different classes of opiate receptor, others might be non-specific, involving interaction with sites other than opiate receptors.

\footnotetext{
* To whom correspondence should be addressed.
} 
Included among the excitatory actions of opiates is the production of convulsions by the opiate alkaloids ${ }^{13,14,20,41,47,48}$ and peptides ${ }^{19,20,46,48}$. It is unclear if opiate induction of seizures is mediated by opiate receptors, since large concentrations of morphine are required $20,47,48$ and the resultant seizures are resistant to naloxone antagonism $20,31,48$. The mechanism of opiate epileptogenesis is also unclear, but two mechanisms have been proposed: (1) presynaptic depression of GABA release $e^{4,37,54}$ and (2) postsynaptic modulation of amino acid responsiveness ${ }^{6,14}$.

Opiates have been reported to antagonize glycine $e^{6,11,12,15,16,28}, \mathrm{GABA}^{14-16}$ and glutamate ${ }^{15-17,23,53,55}$ effects on neuronal firing rate. Opiate antagonism of glycineand GABA-induced inhibition of neuronal firing has generally not been naloxone reversible ${ }^{12,16}$, suggesting the effect is not mediated by opiate receptors. Indeed, an interaction with glycine and GABA receptors rather than opiate receptors is likely, since the opiate alkaloids have been reported to displace $\left[{ }^{3} \mathrm{H}\right]$ strychnine and $\left[{ }^{3} \mathrm{H}\right]$ GABA bound to synaptic membranes ${ }^{14,51}$. In contrast, glutamate-induced firing has been reported to be depressed by opiates in a stereospecific ${ }^{53}$ and naloxone reversible $17,23,53,55$ manner, suggesting an opiate receptor mediated effect. However, naloxone did not reverse opiate depression of glutamate responses in several other studies $^{16,18,45}$.

We investigated opiate actions on spontaneous neuronal activity and postsynaptic amino acid responsiveness using intracellular recording techniques applied to murine spinal cord neurons in primary dissociated cell culture. We report that morphine antagonized postsynaptic glycine and GABA but not glutamate responses. Antagonism of glycine responses was correlated with the induction of paroxysmal depolarizations in cultured spinal cord neurons. Morphine actions on postsynaptic inhibitory amino acid responsiveness and spontaneous activity were not mediated by opiate receptors since the effects were not naloxone reversible, stereospecific, or produced by the opioid peptide [D-Ala $\left.{ }^{2}\right]$-Met-enkephalinamide.

\section{MATERIALS AND METHODS}

\section{Cell culture}

Neuronal cultures were prepared by dissecting spinal cords with attached dorsal root ganglia from 12-14-day-old fetal mice ${ }^{43}$. The tissue was mechanically dissociated to a single cell suspension which was plated on $35 \mathrm{~mm}$ collagen-coated culture plates at a density of $1 / 4$ to $1 / 2$ spinal cord per plate. Initial culture medium consisted of $80 \%$ Eagle's minimum essential medium, $10 \%$ horse serum, and $10 \%$ fetal calf serum. Approximately 4 days after initial plating, $5^{\prime}$-fluoro- 2 '-deoxyuridine and uridine were added to the cultures to inhibit the division of non-neuronal background cells after which growth medium was modified to $90 \%$ Eagle's minimum essential medium and $10 \%$ horse serum. Four-to-twelve-week-old cultures were used in electrophysiological experiments.

\section{Intracellular recording}

For electrophysiological studies, cultures were placed on the heated stage $\left(35^{\circ} \mathrm{C}\right)$ 
of an inverted phase contrast microscope which allowed neuronal impalement by a recording electrode under visual control. Intracellular recordings were obtained using $4 \mathrm{M}$ potassium acetate or $3 \mathrm{M}$ potassium chloride filled micropipettes which had a resistance of 25-50 M . A modified bridge circuit allowed simultaneous current passage and voltage recording by single microelectrodes. Data were recorded on a 6channel polygraph.

Prior to recording of spontaneous electrical activity, growth medium was poured from the culture and replaced by Dulbecco's phosphate-buffered saline(DPBS). A thin coat of mineral oil over the DPBS retarded evaporation. Recordings were obtained from each culture over a $3 \mathrm{~h}$ period. The initial hour consisted of recording spontaneous activity in control medium. At the end of both the first and second hours, opiates were added to the culture using a microliter pipetter. Five to ten neurons were impaled during each hour.

\section{Iontophoresis of amino acids during superfusion}

Experiments were performed in DPBS containing $10 \mathrm{mM}$ magnesium ion to suppress spontaneous activity. GABA, glycine and glutamate (all $0.5 \mathrm{M} ; \mathrm{pH} 3.2,1.8$, and 9.1 , respectively) were applied by iontophoresis using constant current pulses $(500$ $\mathrm{ms}$ ) of 0-40 nA.

Morphine (Mallinckrodt), levorphanol and dextrorphan (Hoffmann-LaRoche), naloxone (Endo Laboratories), and [D-Ala ${ }^{2}$ ]-Met-enkephalinamide (Calbiochem) were superfused through the culture at a rate of $0.6 \mathrm{ml} / \mathrm{min}$ by a peristaltic pump. Neurons were impaled in control medium, the peristaltic pump was started and the superfusion rate was then unaltered for the duration of the recording. Iontophoretic current was adjusted to obtain amino acid responses of $10-20 \mathrm{mV}$ in control medium with responses evoked every $0.5-1.0 \mathrm{ml}$ of superfusate. Opiate containing buffer was superfused through the culture until 2-3 successive amino acid responses of similar amplitude were obtained after which the opiate was rinsed from the culture. Cells were often held for 3-4 h allowing up to 6 morphine concentrations to be tested on single

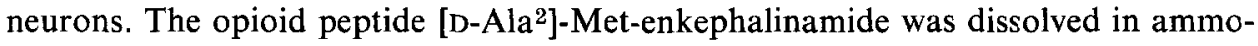
nium acetate buffer $(\mathrm{pH}=4.5)$ and then frozen in aliquots to be used in a single experiment. To prevent loss of peptide during superfusion, the medium contained $0.1 \%$ bovine serum albumin and $50 \mu \mathrm{g} / \mathrm{ml}$ bacitracin.

Recording micropipettes were filled with $3 \mathrm{M}$ potassium chloride; thus, chloride ions were injected into neurons, thereby altering the reversal potential for GABA and glycine responses from about -60 to about $-20 \mathrm{mV}$. Since neurons were hyperpolarized to a potential of $-80 \mathrm{mV}$, approximately $60 \mathrm{mV}$ separated membrane potential from GABA and glycine reversal potentials and all amino acid responses were depolarizing.

\section{RESULTS}

Opiate alkaloids produced paroxysmal depolarizing events

Spontaneous activity recorded from neurons in control medium consisted of 


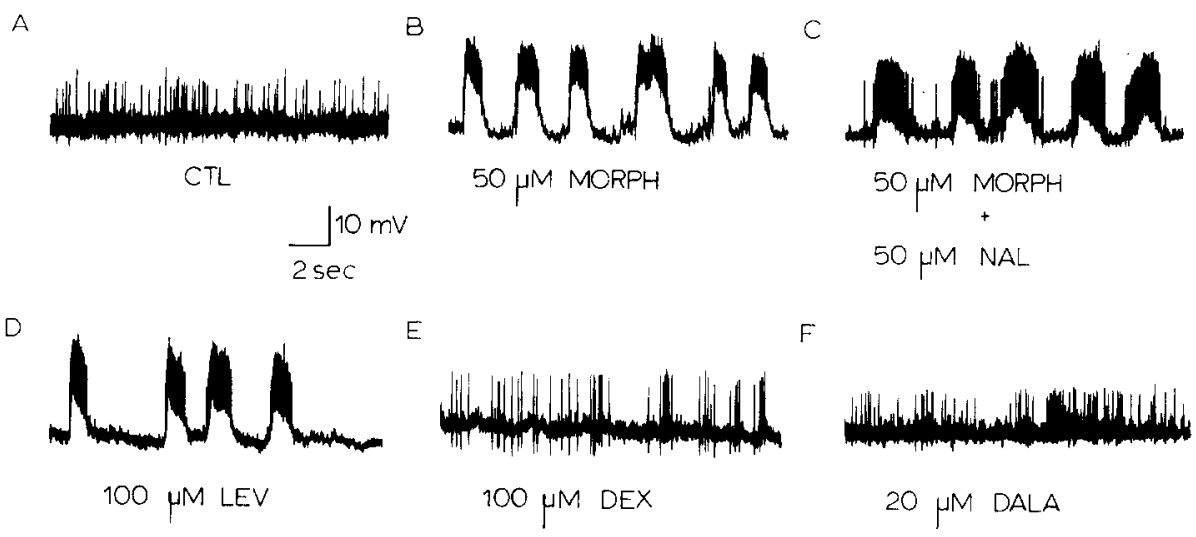

Fig. 1. Opiate alkaloids-induced paroxysmal electrical activity. Intracellular recordings of spontaneous activity during bath application of opiates. Action potentials were truncated due to the low frequency response of the pen recorder. Morphine (MORPH)-induced PDE were not antagonized by naloxone (NAL). Levorphanol (LEV) but not the $\mathrm{L}$ - enantiomer dextrorphan (DEX) nor [D-Ala ${ }^{2}$ Met-enkephalinamide (DALA) produced PDE. Resting membrane potentials for figures A-F were $-68,-60,-54,-52,-60$ and $-65 \mathrm{mV}$, respectively.

randomly occurring action potentials and inhibitory and excitatory postsynaptic potentials (Fig. 1A). Fewer than $10 \%$ of the neurons, however, showed a pattern of activity consisting of a burst of action potentials riding on a depolarization greater than $8 \mathrm{mV}$ with a duration of $800 \mathrm{~ms}$ to $2 \mathrm{~s}$. The incidence of these paroxysmal depolarizing events (PDE) ${ }^{29}$ was increased by morphine (Fig. 1B). Naloxone, administered at 0.2-2 times the concentration of morphine, did not antagonize morphine-induced PDE, although it may have slightly attenuated the amplitude of the depolarizations (Fig. 1C). The opiate alkaloids produced PDE stereospecifically with $100 \mu \mathrm{M}$ levorphanol inducing PDE in $60 \%$ of the neurons (Fig. 1D, Fig. 2), but the

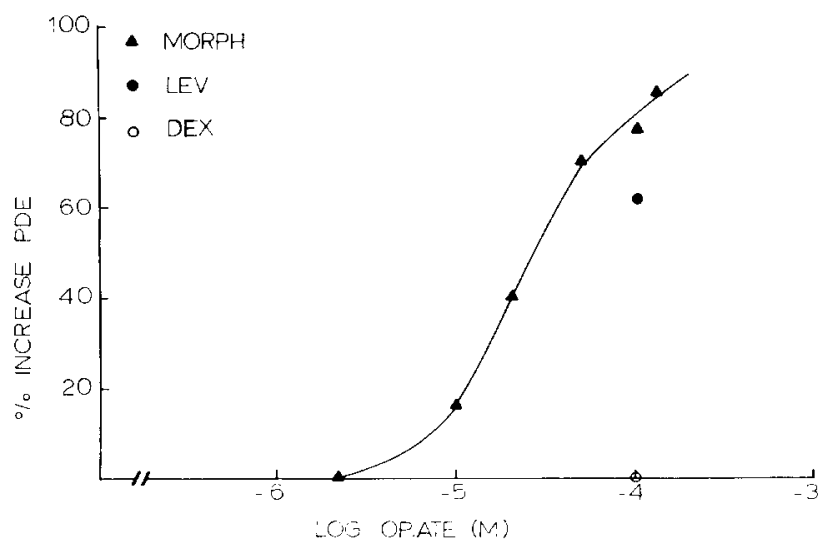

Fig. 2. Opiate alkaloids increased the occurrence of PDE in a dose-dependent and stereospecific manner. Semilogarithmic plot of the percentage of neurons having PDE as a function of morphine concentration. At $100 \mu \mathrm{M}$ concentrations of the enantiomers, levorphanol induced PDE with potency similar to morphine while dextrorphan was ineffective. Data were corrected for baseline occurrence of PDE in control medium. 
$\mathrm{L}(+)$ enantiomer dextrorphan not altering spontaneous baseline activity (Figs. 1E, 2). The opioid peptide [D-Ala ${ }^{2}$-Met-enkephalinamide, did not increase the occurrence of PDE at concentrations of $200 \mathrm{nM}$ to $20 \mu \mathrm{M}$ (Fig. 1F). The incidence of PDE was increased by morphine at concentrations of $10-125 \mu \mathrm{M}$ in a dose-dependent manner (Fig. 2). Morphine induced PDE in $50 \%$ of neurons $\left(\mathrm{ED}_{50}\right)$, corrected for baseline occurrence of PDE in control medium, at a concentration of $25 \mu \mathrm{M}$ (Fig. 2). Recordings were obtained from 16 to 27 neurons in two to three cultures at each morphine concentration.

\section{Morphine antagonized glycine- and GABA-mediated postsynaptic responses}

Morphine reversibly antagonized postsynaptic glycine (19 of 19 cells) and GABA (12 of 12 cells) responses (Fig. 3A). Glutamate responses (9 cells) were unaltered by morphine concentrations as high as $1.5 \mathrm{mM}$. Antagonism of glycine responses by morphine occurred over 1.5-750 $\mu \mathrm{M}$ with an $\mathrm{ED}_{50}$ of $35 \mu \mathrm{M}$ (Fig. 4). Approximately ten-fold higher concentrations of morphine, $75 \mu \mathrm{M}$ to $1.5 \mathrm{mM}$ (ED ${ }_{50}$ $=475 \mu \mathrm{M}$ ), were required to antagonize GABA responses (Figs. 3A, 4). No changes in resting membrane potential or conductance were apparent during superfusion of opiate alkaloids through the cultures at concentrations which completely attenuated glycine and GABA response amplitudes.

At a concentration of $20 \mu \mathrm{M}$, the opioid peptide [D-Ala ${ }^{2}$ ]-Met-enkephalinamide did not affect the amplitude of postsynaptic glycine $(n=8)$, GABA $(n=6)$, or

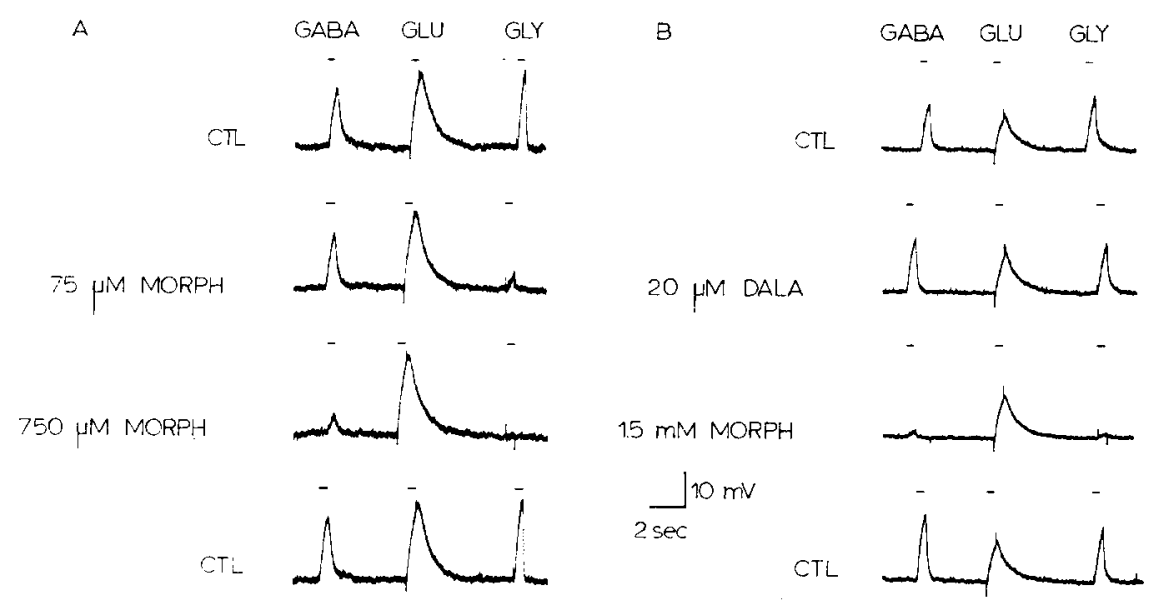

Fig. 3. Opiate alkaloids depressed postsynaptic glycine and GABA but not glutamate responses. A. Dose-dependent actions of morphine on iontophoretically evoked glycine, GABA, and glutamate responses recorded from a single spinal cord neuron. Superfusion of the culture with medium containing $75 \mu \mathrm{M}$ morphine attenuated glycine but not GABA or glutamate responses. Morphine at a concentration of $750 \mu \mathrm{M}$ also diminished GABA responses while glutamate responses were

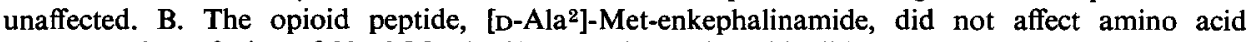
responses. Superfusion of $20 \mu \mathrm{M}$ [D-Ala ${ }^{2}$-Met-enkephalinamide did not alter GABA, glutamate, or glycine responses, while application of $1.5 \mathrm{mM}$ morphine to the same neuron attenuated glycine and GABA responses without altering glutamate responses. Recordings in this and subsequent figures were obtained with $3 \mathrm{M}$ potassium chloride-filled micropipettes. Membrane potentials were hyperpolarized to approximately $-80 \mathrm{mV}$. 


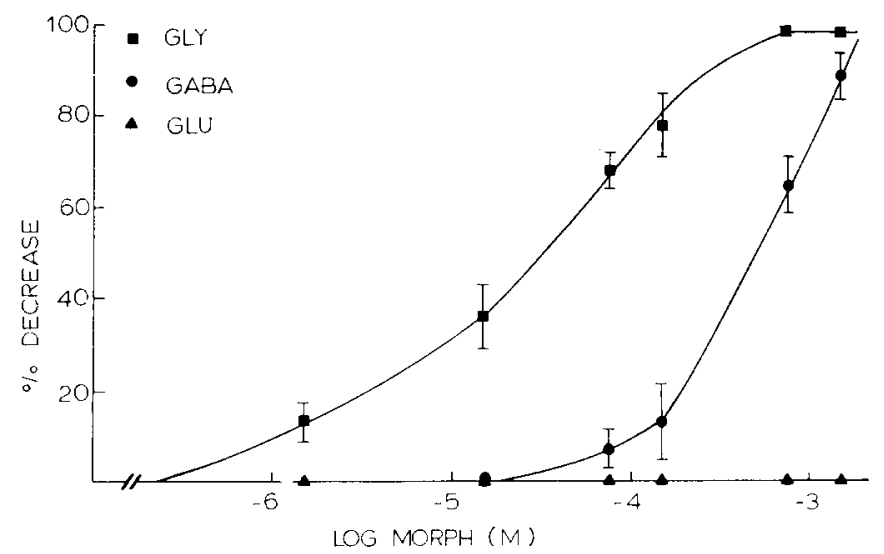

Fig. 4. Morphine attenuation of glycine and GABA responses was dose dependent. Morphine depressed glycine and GABA responses at concentrations exceeding $1.5 \mu \mathrm{M}\left(\mathrm{ED}_{50}=35 \mu \mathrm{M}\right)$ and 75 $\mu \mathrm{M}\left(\mathrm{ED}_{50}=475 \mu \mathrm{M}\right)$, respectively. Glutamate responses were unaffected by morphine over the concentration range tested $(1.5 \mu \mathrm{M}$ to $1.5 \mathrm{mM})$. Mean data from 3-9 neurons are given for each concentration tested. Bars represent standard error of the mean.

glutamate $(\mathrm{n}=8)$ responses (Fig. 3B). Although opioid peptide actions have been found to desensitize rapidly ${ }^{21}$, it is unlikely that desensitization explains the observed lack of effect by [D-Ala ${ }^{2}$-Met-enkephalinamide. Data were obtained from neurons in multiple (5) cultures, and amino acid responses were not antagonized in neurons which had not previously been exposed to the opioid peptide. Furthermore, application of $1.5 \mathrm{mM}$ morphine almost totally reduced GABA and glycine responses in neurons which had been unaffected by [D-Ala $\left.{ }^{2}\right]$-Met-enkephalinamide.

To determine if opiate antagonism of glycine and GABA responses was stereospecific, 100 and $500 \mu \mathrm{M}$ concentrations of both levorphanol and dextrorphan were tested. Determination of relative levorphanol and dextrorphan potency in antagonizing the responses of neurons to glycine and GABA was obtained by testing equal concentrations of the enantiomers during each recording. Levorphanol antagonized glycine responses with potency similar to morphine while dextrorphan was less potent (Fig. 5, 6). Glycine responses were reduced by mean values of $72 \%$ by levorphanol and $12 \%$ by dextrorphan at enantiomer concentrations of $100 \mu \mathrm{M}(\mathrm{n}=$ 5) (Fig. 6). The effects were dose-dependent with $500 \mu \mathrm{M}$ concentrations of levorphanol and dextrorphan $(\mathbf{n}=3)$ reducing glycine responses with mean values of $92 \%$ and $64 \%$, respectively (Fig. 6). Glycine responses were significantly more reduced by levorphanol than dextrorphan at both $100 \mu \mathrm{M}$ (paired $t$-test, $P<0.005$, one-tailed) and $500 \mu \mathrm{M}$ (paired $t$-test, $P<0.01$, one-tailed) concentrations. At $100 \mu \mathrm{M}$ concentrations, levorphanol was at least 3 times more potent than dextrorphan in attenuating glycine responses (paired $t$-test, $P<0.05$, one-tailed). The difference in the effectiveness of the enantiomers to attenuate glycine responses was not as marked at $500 \mu \mathrm{M}$ concentrations, since levorphanol concentrations were approached which maximally depressed glycine responses.

In contrast to effects on glycine responses, $100 \mu \mathrm{M}$ concentrations of levor- 


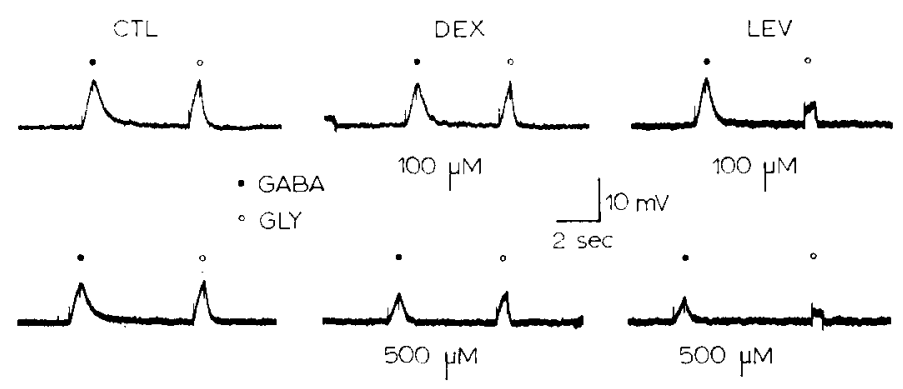

Fig. 5. Opiate alkaloid effects on glycine, but not GABA responses, were weakly stereospecific. The enantiomers, levorphanol and dextrorphan, were tested at concentrations of $100 \mu \mathrm{M}$ and $500 \mu \mathrm{M}$ on a single neuron. At $100 \mu \mathrm{M}$ concentrations, levorphanol but not dextrorphan attenuated the glycine response and neither enantiomer affected the GABA response amplitude. The enantiomers at $500 \mu \mathrm{M}$ concentrations were equipotent in attenuating GABA responses. The depolarization associated with iontophoresis of glycine during superfusion of $500 \mu \mathrm{M}$ levorphanol was a coupling artifact, not a glycine response.

phanol and dextrorphan $(n=4)$ only minimally attenuated GABA response amplitude and did so with similar potencies; each depressed GABA responses with a mean of $5 \%$ (Fig. 6). Levorphanol and dextrorphan at $500 \mu \mathrm{M}$ concentrations $(n=5)$ reduced GABA responses with mean values of $65 \%$ and $58 \%$, respectively. Thus, the enantiomers were equipotent in reducing GABA response amplitude at $500 \mu \mathrm{M}$ concentrations (paired $t$-test, $P>0.1$ one-tailed). The effects of levorphanol and dextrorphan at $100 \mu \mathrm{M}$ concentrations were not tested for a statistical difference since most neurons did not respond to either of the enantiomers at this concentration.

Naloxone was tested for its ability to antagonize depression of glycine responses by morphine. Morphine at $75 \mu \mathrm{M}$ was chosen since it produced unambiguous but

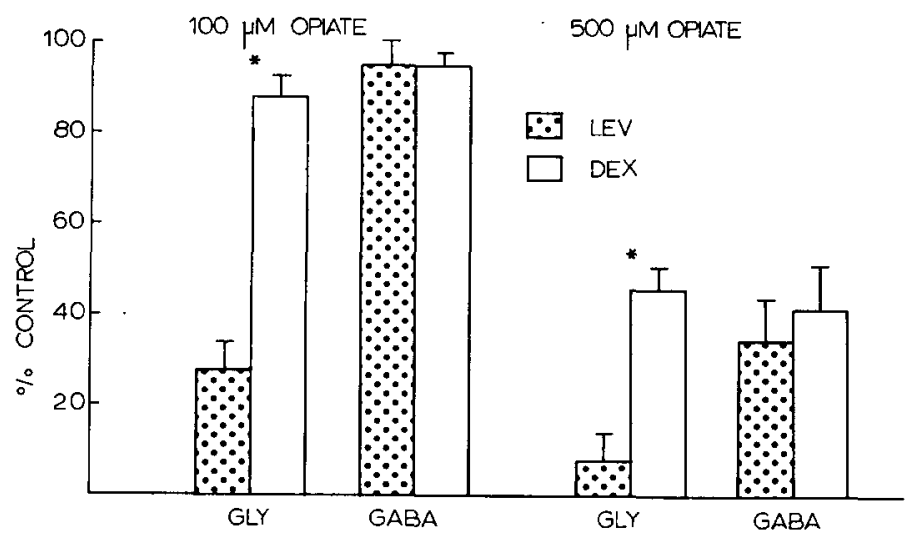

Fig. 6. Opiate effects on glycine responses were weakly stereospecific. Mean glycine and GABA response amplitudes during superfusion of $100 \mu \mathrm{M}$ and $500 \mu \mathrm{M}$ concentrations of levorphanol and dextrorphan expressed as a percentage of response amplitude observed in control medium. Levorphanol was more potent than dextrorphan in depressing glycine-responses at $100 \mu \mathrm{M}(\mathrm{n}=5)$ and 500 $\mu \mathrm{M}(\mathrm{n}=3)$ concentrations. GABA responses were depressed equipotently by the enantiomers at 100 $\mu \mathrm{M}(\mathrm{n}=4)$ and $500 \mu \mathrm{M}(\mathrm{n}=5)$ concentrations. Bars represent standard error of the mean. A statistically significant difference in enantiomer potency as determined by a paried $t$-test is denoted by an asterisk. 


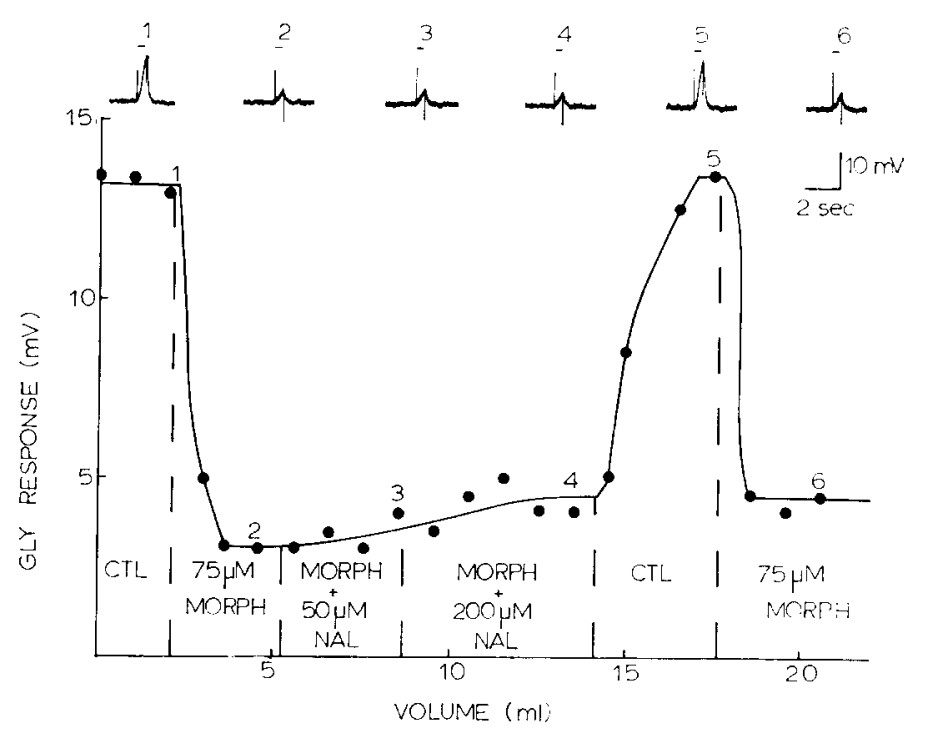

Fig. 7. Naloxone did not reverse morphine depression of glycine responses. Glycine response amplitude is plotted as a function of the volume superfused through the culture. Control glycine responses were about $13 \mathrm{mV}$ (1). Superfusion of medium containing $75 \mu \mathrm{M}$ morphine attenuated glycine response amplitude to about $4 \mathrm{mV}$ (2). Morphine-induced attenuation was not reversed by addition of either 50 $\mu \mathrm{M}$ (3) or $200 \mu \mathrm{M}$ (4) naloxone to the superfusion medium. Superfusion with control medium restored the control glycine amplitude (5). Application of $75 \mu \mathrm{M}$ morphine again antagonized the glycine responses (6).

incomplete diminution of glycine responses (mean reduction $70 \%$ ). Addition of naloxone in concentrations of $50 \mu \mathrm{M}$ to $1 \mathrm{mM}$ to superfusion medium containing 75 $\mu \mathrm{M}$ morphine did not reverse depression of glycine responses by morphine $(n=4)$ (Fig. 7). Subsequent rinsing of morphine and naloxone from the culture restored glycine responses to control amplitude.

\section{DISCUSSION}

\section{Convulsant actions of opiates}

We have demonstrated that opiate alkaloids altered spontaneous neuronal activity, producing large amplitude, long-duration depolarizations with associated action potentials (PDE). Convulsants such as penicillin, pentylenetetrazol, bicuculline, and picrotoxin have been reported to produce a similar pattern of activity in cultured spinal cord neurons ${ }^{29}$. PDE may be an in vitro equivalent of paroxysmal depolarization shifts (PDS) observed during intracellular recording from neurons in cortical epileptic foci ${ }^{32,33,42}$ and of bursting recorded from spinal motoneurons following convulsant application ${ }^{44}$. Therefore, opiate alkaloid-induced PDE in cultured spinal cord neurons might serve as a model of morphine produced convulsions in vivo.

To determine if opiate alkaloids produced PDE by interaction with opiate receptors, the effect was tested for stereospecificity, naloxone reversibility, and agonist properties of the opioid peptides. The production of paroxysmal activity in the culture 
was stereospecific, but neither naloxone-reversible nor [D-Ala $\left.{ }^{2}\right]-M e t-e n k e p h a l i n a-$ mide-induced. These data indicate that the convulsant actions of opiates on cultured spinal cord neurons were not mediated by opiate receptors and, hence, were nonspecific. This contrasts with findings implicating opiate receptors in seizure induction. Intracerebroventricular administration of the enkephalins or morphine has been reported to produce convulsions which were antagonized by high concentrations of naloxone ${ }^{19,20,48}$. Opioid peptides have also been shown to induce naloxone-reversible PDS in hippocampal neurons ${ }^{21}$. However, the opiate alkaloids have been reported to induce seizures by a non-opiate-receptor-mediated mechanism, suggested by the agonist actions of naloxone and the equipotency of opiate enantiomers as convulsants ${ }^{13,14}$. Thus, it is likely that opiate-mediated convulsions are produced by two mechanisms: an interaction of the opiate alkaloids and peptides with opiate receptors and by an action of the opiate alkaloids on neutral amino acid (glycine and GABA) receptors.

\section{Morphine antagonism of glycine and $G A B A$ responses}

We have found that morphine antagonized postsynaptic glycine and GABA, but not glutamate responses. These data are in agreement with observations in vivo that morphine antagonized glycine ${ }^{6,11,12,15,16,28}$ and, at higher iontophoretic currents, GABA $^{14-16}$ induced depression of unit firing. In contrast to our findings, morphine and the opioid peptides have been reported to depress glutamate excitatory actions on neuronal firing in a naloxone-reversible $1,17,23,53,55$ and stereospecific ${ }^{53}$ manner. Opiate depression of glutamate-induced firing was not reversed by naloxone in several other studies $^{16,18,45}$. Our results suggest that opiates do not directly antagonize glutamate action on glutamate receptors, but do not rule out the possibility of an opiate receptor interaction with glutamate receptors.

It is unlikely that antagonism of amino acid responses was mediated by opiate receptors since the effect was not produced by the opioid peptide [D-Ala $\left.{ }^{2}\right]-M e t-e n k e p h-$ alinamide, antagonized by naloxone, or highly stereospecific. While levorphanol was three-fold more potent than dextrorphan in attenuating glycine responses, the observed difference was 10-100 times less than predicted for an opiate-receptor-mediated phenomenon $^{3,5,40}$. Furthermore, concentrations of morphine required for antagonism of glycine- and GABA-mediated responses were higher than expected for an opiatereceptor-mediated effect. High levels of analgesia occur at $1 \mu \mathrm{M}$ brain concentrations of morphine ${ }^{22,35}$, whereas a similar concentration of morphine attenuated glycine response amplitude by less than $10 \%$. In preparations where opiate concentration could be accurately determined and correlated with a physiological action, opiates have been found to exert effects in the low nanomolar concentration range $38,39,49,52$. Therefore, there is a 100-1000-fold difference in potency between morphine antagonism of inhibitory amino acid responses and opiate-receptor-mediated effects. These data are consistent with antagonism of inhibitory amino acid responses underlying opiate-mediated convulsions and not analgesia since 100-1000 times the analgesic dose of morphine is required for the induction of seizures ${ }^{41,47}$.

Morphine antagonized postsynaptic glycine and GABA responses in the absence 
of an effect on resting membrane potential or conductance. Both amino acids increase membrane conductance to chloride ions ${ }^{2}$. Therefore, morphine might simultaneously depress neuronal responsiveness to GABA and glycine by binding to a site which modulates chloride channel conductance. However, such a mechanism is unlikely since GABA and glycine responses were depressed with differing potency by the opiates: the dose response curves for depression of GABA and glycine responses were separated by one log unit, and antagonism of glycine but not GABA responses was stereospecific. Furthermore, opiate alkaloids have been shown to displace $\left[{ }^{3} \mathrm{H}\right] \mathrm{GABA}$ and $\left[{ }^{3} \mathrm{H}\right]$ strychnine with low affinity from GABA and glycine receptors ${ }^{14,51}$, respectively. Thus, it is likely that opiate alkaloids bind to glycine and GABA receptors as do strychnine ${ }^{10}$ and bicuculline ${ }^{7,8}$, rather than to chloride channels.

\section{Antagonism of inhibitory amino acids: correlation with paroxysmal activity}

Morphine produced PDE over a concentration range similar to that producing antagonism of glycine responses (Fig. 8), while morphine dose-response curves for production of PDE and antagonism of GABA responses were separated by one log unit with PDE occurring at lower morphine concentrations. Since GABA and glycine are inhibitory transmitters with a ubiquitous distribution in the central nervous system $^{9,24,26}$, it is likely that alteration of the actions of these amino acids would have profound effects on neuronal activity. Indeed, a decrease in amino acid mediated postsynaptic inhibition has been proposed as a mechanism of convulsant action ${ }^{29,34}$.

The good correlation between antagonism of postsynaptic glycine responses and increased PDE in spinal cord neurons was not surprising since glycine is the principal inhibitory transmitter in spinal cord 50 . Our data suggest that glycine-mediated inhibition must be reduced by approximately $20 \%$ for the production of paroxysmal activity in the culture. At supraspinal levels, GABA is the principle inhibitory transmitter ${ }^{27}$ and, therefore, the dose-response curve for morphine-mediated PDE might be expected to be shifted to the right.

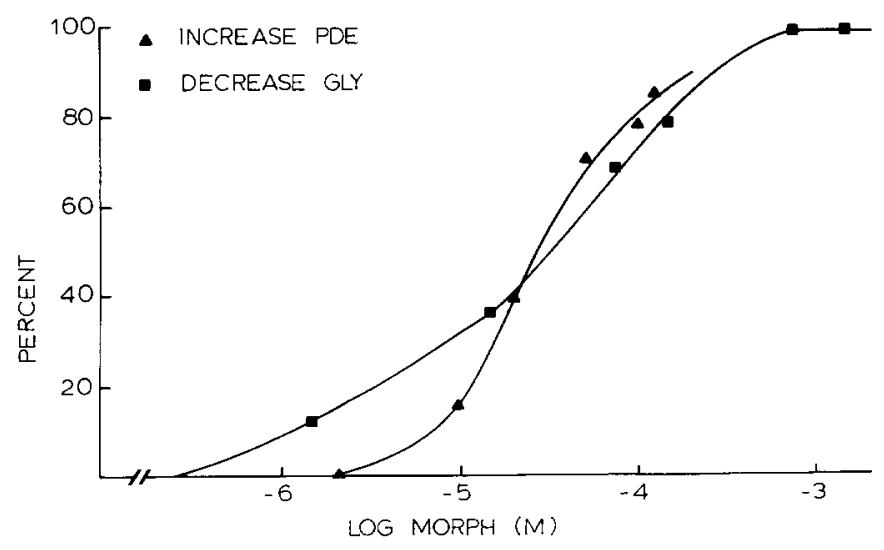

Fig. 8. Morphine attenuation of glycine responses and induction of PDE occurred over similar concentration ranges. Glycine responses were approximately $20 \%$ attenuated at threshold morphine concentration for PDE. ED 50 s for attenuation of glycine responses and induction of PDE were $35 \mu \mathrm{M}$ and $25 \mu \mathrm{M}$, respectively. 


\section{ACKNOWLEDGEMENTS}

The authors thank Kathy Lundquist for her excellent secretarial assistance and Frank Wilk for his skillful maintenance of the neuronal cell cultures. M.A.W. was supported by a NIMH-NRSA 12479 fellowship. R.L.M. was supported by NIH Research Grant NS 15225 and Research Career Development Award NS 00408. This work was submitted in partial fulfillment of the requirements for the degree of Doctor of Philosophy in Neurosciences at University of Michigan by M.A.W.

\section{REFERENCES}

1 Barker, J. L., Smith, T. G. and Neale, J. H., Multiple membrane actions of enkephalin revealed using cultured spinal neurons, Brain Research, 154 (1978) 153-158.

2 Barker, J. L. and Ransom, B. R., Amino acid pharmacology of mammalian central neurones grown in tissue culture, J. Physiol. (Lond.), 280 (1978) 331-354.

3 Beckett, A. H. and Casy, A. F., Synthetic analgesics: stereochemical considerations, J. Pharm. Pharmacol., 6 (1954) 986-999.

4 Brennan, M. J. W., Cantrill, R. C. and Wylie, B. A., Modulation of synaptosomal GABA release by enkephalin, Life Sci., 27 (1980) 1097-1101.

5 Chang, K.-J., Miller, R. J. and Cuatrecasas, P., Interaction of enkephalin with opiate receptors in intact cultured cells, Mol. Pharmacol., 14 (1978) 961-970.

6 Curtis, D. R. and Duggan, A. W., The depression of spinal inhibition by morphine, Agents Actions, 1 (1969) 14-19.

7 Curtis, D. R., Duggan, A. W., Felix, D. and Johnston, G. A. R., Bicuculline an antagonist of GABA and synaptic inhibition in the spinal cord of the cat, Brain Research, 32 (1971) 69-96.

8 Curtis, D. R. and Felix, D., The effect of bicuculline upon synaptic inhibition in the cerebral and cerebellar cortices of the cat, Brain Research, 34 (1971) 301-321.

9 Curtis, D. R. and Johnston, G. A. R., Amino acid transmitters in the mammalian central nervous system, Ergeb. Physiol. biol. Chem. exp. Pharmakol., 69 (1974) 97-188.

10 Davidoff, R. A., Aprison, M. H. and Werman, R., The effects of strychnine on the inhibition of interneurons by glycine and $\gamma$-aminobutyric acid, Int. J. Neuropharmacol, 8 (1969) 191-194.

11 Davies, $\mathbf{J}$. and Dray, A., Effects of enkephalin and morphine on Renshaw cells in feline spinal cord, Nature (Lond.), 262 (1976) 603-604.

12 Davies, J. and Duggan, A. W., Opiate agonist-antagonist effects on Renshaw cells and spinal interneurones, Nature (Lond.), 250 (1974) 70-71.

13 Dingledine, R. and Goldstein, A., Lethality of the morphinan isomers levorphanol and dextrorphan, Brit. J. Pharmacol., 48 (1973) 718-720.

14 Dingledine, R., Iversen, L. L. and Breuker, E., Naloxone as a GABA antagonist: evidence from iontophoretic, receptor binding and convulsant studies, Europ. J. Pharmacol., 47 (1978) 19-27.

15 Dostrovsky, J. and Pomeranz, B., Morphine blockade of amino acid putative transmitters on cat spinal cord sensory interneurones, Nature New Biol., 246 (1973) 222-224.

16 Dostrovsky, J. O. and Pomeranz, B., Interaction of iontophoretically applied morphine with responses of interneurons in cat spinal cord, Exp. Neurol., 52 (1976) 325-338.

17 Duggan, A. W. and Hall, J. G., Morphine, naloxone and the responses of medial thalamic neurones of the cat, Brain Research, 122 (1977) 49-57.

18 Duggan, A. W., Hall, J. G. and Headley, P. M., Suppression of transmission of nociceptive impulses by morphine: selective effects of morphine administered in the region of the substantia gelatinosa, Brit. J. Pharmacol., 61 (1977) 65-76.

19 Frenk, H., McCarty, B. C. and Liebeskind, J. C., Different brain areas mediate the analgesic and epileptic properties of enkephalin, Science, 200 (1978) 335-337.

20 Frenk, H., Urca, G. and Liebeskind, J. C., Epileptic properties of leucine-and methionine-enkephalin: comparison with morphine and reversibility by naloxone, Brain Research, 147 (1978) 327-337.

21 Gähwiler, B. H., Excitatory action of opioid peptides and opiates on cultured hippocampal pyramidal cells, Brain Research, 194 (1980) 193-203.

22 Herz, A. and Teschemacher, H.-J., Activities and sites of antinociceptive action of morphine-like analgesics, Adv. Drug Res., 6 (1971) 79-119. 
23 Hill, R. G. and Pepper, C. M., Selective effects of morphine on the nociceptive responses of thalamic neurones in the rat, Brit. J. Pharmacol., 64 (1978) 137-143.

24 Iversen, L. L. and Bloom, F. E., Studies of the uptake of $\left[{ }^{3} \mathrm{H}\right] \mathrm{GABA}$ and $\left[{ }^{3} \mathrm{H}\right] \mathrm{glycine}$ in slices and homogenates of rat brain and spinal cord by electron microscope and autoradiography, Brain Research, 41 (1972) 131-143.

25 Jessell, T. M. and Iversen, L. L., Opiate analgesics inhibit substance P release from rat trigeminal nucleus, Nature (Lond.), 268 (1977) 549-551.

26 Krnjevic, K., Chemical nature of synaptic transmission in vertebrates, Physiol. Rev., 54 (1974) 418-450.

27 Krnjevic, K. and Schwartz, S., The action of $\gamma$-aminobutyric acid on cortical neurones, Exp. Brain Res., 3 (1967) 320-326.

28 Lodge, D., Headley, P. M., Duggan, A. W. and Biscoe, T. J., The effects of morphine, etorphine, and sinomenine on the chemical sensitivity and synaptic responses of Renshaw cells and other spinal neurones in the rat, Europ. J. Pharmacol., 26 (1974) 277-284.

29 Macdonald, R. L. and Barker, J. L., Specific antagonism of GABA-mediated postsynaptic inhibition in cultured mammalian spinal cord neurons: a common mode of convulsant action, Neurology, 28 (1978) 325-330.

30 Macdonald, R. L. and Nelson, P. G., Specific opiate-induced depression of transmitter from dorsal root ganglion cells in culture, Science, 199 (1978) 1449-1451.

31 Martin, W. R., Opioid antagonists, Pharmacol. Rev., 19 (1967) 463-521.

32 Matsunoto, H., Cortical cellular phenomena in experimental epilepsy: interictal manifestations, Exp. Neurol., 9 (1964) 286-304.

33 Matsumoto, H., Ayala, G. F. and Gumnit, R. J., Neuronal behavior and triggering mechanism in cortical epileptic focus, J. Neurophysiol., 32 (1969) 688-703.

34 Meldrum, B. S., Epilepsy and $\gamma$-aminobutyric acid-mediated inhibition, Int. Rev. Neurobiol., 17 (1975) 1-36.

35 Miller, J. W. and Elliott, H. W., Rat tissue levels of carbon-14 labeled analgesics as related to pharmacological activity, J. Pharmacol. exp. Ther., 113 (1954) 283-291.

36 Mudge, A. W., Leeman, S. E. and Fishbach, G. D., Enkephalin inhibits release of substance P from sensory neuron in culture and decreases action potential duration, Proc. nat. Acad. Sci. U.S.A., 76 (1979) 526-530.

37 Nicoll, R. A., Alger, B. E. and Jahr, C. E., Enkephalin blocks inhibitory pathways in the vertebrate CNS, Nature (Lond.), 287 (1980) 22-25.

38 North, R. A. and Tonini, M., The mechanism of action of narcotic analgesics in the guinea-pig ileum, Brit. J. Pharmacol., 61 (1977) 541-549.

39 Pepper, C. M. and Henderson, G., Opiates and opioid peptides hyperpolarize locus coeruleus neurons in vitro, Science, 209 (1980) 394-396.

40 Pert, C. B. and Snyder, S. H., Properties of opiate-receptor binding in rat brain, Proc. Nat. Acad. Sci. U.S.A., 70 (1973) 2243-2247.

41 Pinto Corrado, A. and Longo, V. G., An electrophysiological analysis of the convulsant action of morphine, codeine, and thebaine, Arch. int. Pharmacodyn., 132 (1961) 255-269.

42 Prince, D. A., The depolarization shift in 'epileptic' neurons, Exp. Neurol., 21 (1968) 467-485.

43 Ransom, B. R., Neale, E., Henkart, M., Bullock, P. N. and Nelson, P. G., Mouse spinal cord in cell culture. I. Morphology and intrinsic neuronal electrophysiologic properties, J. Neurophysiol., 40 (1977) 1132-1150.

44 Schwindt, P. and Crill, W., Role of persistent inward current in motoneurons bursting during spinal seizures, J. Neurophysiol., 43 (1980) 1296-1318.

45 Segal, M., Morphine and enkephalin interactions with putative neurotransmitters in rat hippocampus, Neuropharmacology, 16 (1977) 587-592.

46 Snead, $O$. C. III and Bearden, L. J., Anticonvulsants specific for petit mal antagonize epileptogenic effect of leucine enkephalin, Science, 210 (1031-1033).

47 Tatum, A. L., Seevers, M. H. and Collins, K. H., Morphine addiction and its physiological interpretation based on experimental evidences, J. Pharmacol. Exp. Ther., 36 (1929) 447-475.

48 Urca, G., Frenk, H., Liebeskind, J. C. and Taylor, A. N., Morphine and enkephalin: analgesic and epileptic properties, Science, 197 (1977) 83-86.

49 Waterfield, A. A., Smokcum, R. W. J., Hughes, J., Kosterlitz, H. W. and Henderson, G., In vitro pharmacology of the opioid peptides, enkephalins and endorphins, Europ. J. Pharmacol., 43 (1977) $107-116$. 
50 Werman, R., Davidoff, R. A. and Aprison, M. H., Inhibitory action of glycine on spinal neurons in the cat, J. Neurophysiol., 31 (1968) 81-95.

51 Werz, M. A., Baum, K., Young, A. B. and Macdonald, R. L., Opiate alkaloid effects on glycineand GABA-mediated postsynaptic inhibition: correlation with paroxysmal activity, Neurosci. Abstr., 7 (1981) 578.

52 Williams, J. T. and North, R. A., Effects of endorphins on single myenteric neurons, Brain Research, 165 (1979) 57-65.

53 Zieglgänsberger, W. and Bayerl, H., The mechanism of inhibition of neuronal activity by opiates in the spinal cord of cat, Brain Research, 115 (1976) 111-128.

54 Zieglgänsberger, W., French, E. D., Siggins, G. R. and Bloom, F. E., Opioid peptides may excite hippocampal pyramidal neurons by inhibiting adjacent inhibitory interneurons, Science, 205 (1979) 415-417.

55 Zieglgänsberger, W. and Tulloch, I. F., The effects of methionine- and leucine-enkephalin on spinal neurones of the cat, Brain Research, 167 (1979) 53-64. 